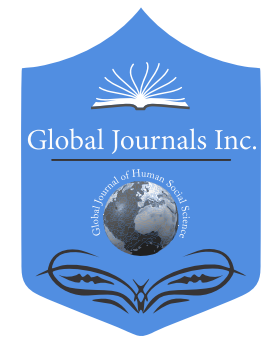

GLOBAL JOURNAL OF HUMAN-SOCIAL SCIENCE: A

ARTS \& HUMANITIES - PSYCHOLOGY

Volume 19 Issue 13 Version 1.0 Year 2019

Type: Double Blind Peer Reviewed International Research Journal

Publisher: Global Journals

Online ISSN: 2249-460X \& Print ISSN: 0975-587X

\title{
Head, Heart and Hands on- Concerning, Concrete, Visual and Creative Methods in Supervision
}

By Christina Löwenborg Introduction- This article describes how creative methodology can be applied to different types of professional conversation. The method is used in part in supervision with professionals working in human care professions, and in part in psychotherapeutic and psychosocial conversations with patients/clients. The article focuses on supervision for professionals working in human care professions. In addition to its beneficial effect in training, supervision has proved to be a strategically important area for the development of professional skills. It has a potentially significant impact on everyday work, given that it is often performed over a protracted period and is closely linked to practical actions (Egelund 2001). Supervision is used to address a number of significant themes.

The issue may have to do with the staff's own feelings towards a client, or the attitudes and methods they apply in their work. It may also center on how professionals can better understand the actions/behavior of their clients. It may have to do with ethical dilemmas in the work, or relationships with working partners. It may concern working relationships within the working group, or feature therapy-like input for personal development (Höjer, Beijer \& Wissö, 2007).

GJHSS-A Classification: FOR Code: 130201

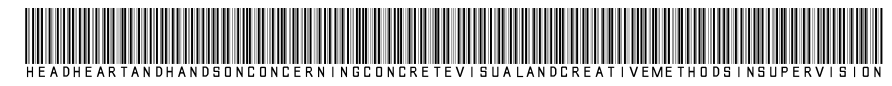

Strictly as per the compliance and regulations of:

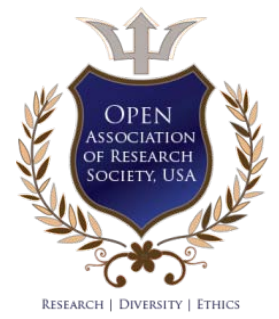

(C) 2019. Christina Löwenborg. This is a research/review paper, distributed under the terms of the Creative Commons AttributionNoncommercial 3.0 Unported License http://creativecommons.org/licenses/by-nc/3.0/), permitting all non-commercial use, distribution, and reproduction in any medium, provided the original work is properly cited. 


\title{
Head, Heart and Hands on- Concerning, Concrete, Visual and Creative Methods in Supervision
}

\author{
Christina Löwenborg
}

\begin{abstract}
This article describes how tangible, visual and creative methodologies can be applied in the context of supervision. The method combines techniques from taping and psychodrama, and uses schema therapeutic points of origin. It comprises both theory and case descriptions that serve to explain and clarify the theoretical perspectives.
\end{abstract}

\section{INTRODUCTION}

T his article describes how creative methodology can be applied to different types of professional conversation. The method is used in part in supervision with professionals working in human care professions, and in part in psychotherapeutic and psychosocial conversations with patients/clients. The article focuses on supervision for professionals working in human care professions. In addition to its beneficial effect in training, supervision has proved to be a strategically important area for the development of professional skills. It has a potentially significant impact on everyday work, given that it is often performed over a protracted period and is closely linked to practical actions (Egelund 2001). Supervision is used to address a number of significant themes.

The issue may have to do with the staff's own feelings towards a client, or the attitudes and methods they apply in their work. It may also center on how professionals can better understand the actions/behavior of their clients. It may have to do with ethical dilemmas in the work, or relationships with working partners. It may concern working relationships within the working group, or feature therapy-like input for personal development (Höjer, Beijer \& Wissö, 2007).

"Head, heart and hands-on" are key concepts that this action methodology comprises.

The Head stands for the cognitive component that allows an "outside-in" perspective and intelligibility of the context. The Heart represents an "inside-out" perspective, an emotional experience of the situation that can contribute to understanding, while hands-on corresponds to action in the situation in question, on the basis of intelligibility and understanding. Emotional learning is accorded a prioritized position as regards interactive processes that supervision entails and is termed the most effective component (a.a.). For this

Author: Stockholm, Sweden licensed psychotherapist and a certified supervisor.e-mail: christina.lowenborg@telia.com reason, it is important to describe a method that underpins emotional learning.

There are long traditions for supervision in Sweden. The idea appeared in the context of child and adult therapy in the 1940s, as a step in the professionalization of child care work in Sweden. During the 1970s, professional support experienced broad expansion to additional activities in the field of human care (Löwenborg, C. \& Nilsson, L., 2001). From a global perspective, however, supervision remains quite rare. For a number of years, the author was involved in a development project with the objective of implementing supervision in Belarus (Löwenborg \& Nilsson, 2005), as new child care mechanisms were being built up in the country at that time. Research (Egelund, T. \& Kvilhaug, 2001) has demonstrated that supervision for professionals comprises a number of meaningful aspects. One significant component is the professional aspect, whose purpose is to develop professional work methods and increase knowledge about theory and research. Given that supervision is targeted at the entire working group within an organization, it also involves an aspect of staff development. It provides continuous support, which helps counteract stress and burn-out in the working group. Shared supervision facilitates working relationships within a working group, and research has also demonstrated that it leads to an increase in the self-awareness of each and every member of the group. The third important aspect in supervision is the client-oriented aspect, i.e. the professionals' target group. Supervision contributes to increasing understanding of and respect for the clients, and to allowing the best possible treatment and interaction (a.a.).

The following section focuses on taping as a method. This is followed by a chapter about psychodrama and a case study drawn from a supervision process, where a combination of taping and psychodrama was used. Next comes a section about schema therapy and how the concept of modes can be utilized in taping. The final chapter presents reflections on combining these specific, visual and creative methods in supervision.

Supervision conversations are used to deal with complex issues and contexts that need to be both understood and processed. Problems and questions 
need to be sorted, delimited and understood, but the process also involves resolving, building up and creating new structures. The theme or issue is placed in context, with the next step being to organize the process around the issue; in that context, it is necessary to combine cognitive and emotional reflections and ideas at the same time.

The specific, visual and creative methodology allows both the cognitive and the emotional perspective to come into play simultaneously, which has a dynamic effect on the process.

\section{What is TAPING?}

Taping is a method that makes conversations visual and tangible by allowing the narrator to build up a scenario using figures and symbols that represent external and internal relations. The narrative thus becomes a palpable and detailed storyline. A visual creation.

The method was developed by Martin Soltvedt (Soltvedt, 2005), a psychologist and child psychotherapist in Norway, who was also the brains behind the approach that came to be known as Child Oriented Family Therapy (BOF).

Taping is a "doing method", an action-oriented method that transforms both the narrator and the conversation guide into two interacting players. Paradoxically, the person guiding the conversation can be more inquisitive, wondering and challenging, and can simultaneously be perceived as less questioning, which helps drive the process forward.

The narrative in taping can demonstrate an "outside-in" and "inside-out" perspective at the same time. In other words, it allows illustration of an external reality simultaneously with an internal one. The method can be applied in many different situations; it can be used to depict a conflict scenario, a vision, someone's life story or two conflicting stories, a network around a person, an inner conflict or a set of circumstances perceived as ambivalent.

The benefit of using taping in a supervision context is that it helps visualize, clarify and concretize the narrative the narrator wishes to present. Taping contributes to creating a shared image, thus ensuring that everyone present is seeing the same picture. One major advantage of supervision is that the creative image generated on the tabletop "stage" stimulates the involvement of the group; this, in turn, makes it easier for all individuals to establish links to their own experiences. Strong participation reinforces the interaction between all those involved and serves as an excellent starting point for supervision going forward.

Supervision is used to process complex issues, and as a narrative is built up and - occasionally simultaneous settings are created, this provides both an overview of the scenario and an understanding of the happening. The specific image narrative generates a perception of reality and elevates the emotional experience.

In taping, the stage is variable. The narration can move through and between past, present and future. It can depict parallel happenings, and it can present an external and an internal reality at one and the same time. Figures can be moved back and forwards. All this facilitates the generation of reflections and the exploration of thoughts and ideas. In supervision, the group members can be invited to air their thoughts and ideas in a specific, tangible manner.

Supervision involves the use of Playmobil ${ }^{\circledR}$ figures, and the ones available represent people of different ages, genders and ethnicity. As they have moving parts, it is possible to highlight their expressions and attitudes by, for example, turning their heads, arms and legs, thus clarifying the relationship between those involved. They can stand close to one another, or far apart. They can turn to face one another or to face away from each other, depending on what is being played out on the stage.

In conjunction with the Playmobil ${ }^{\circledR}$ figures, symbols are used to make the narrative more finely shaded and illustrative. These include tangled balls of cotton that can be placed between figures to illustrate entangled, conflicted relations. There is also a stone, which can be used to represent a weight - possibly a mood of grief or depression. A heart can be used to symbolize a warm relationship. A transparent cube can illustrate a feeling of isolation or exclusion. A telephone can symbolize that the parties are communicating, while a fence can be used to indicate the opposite. The symbols are selected by the narrator, who applies his/her subjective interpretation to them. In taping, the technique of externalization* can be applied through concretizing the externalized problem. For example, a stone can be used to illustrate someone's depression, thus separating the problem from the person so as to clarify that the person is not the depression. This also allows a "dialogue" between the person and the depression. Symbols for animals - such as a horse, dog, cat and bird - can be used to aid descriptions in the narrative. The figures need a delimited space - a stage where the action can take place. Tape and the fence symbol serve as external and internal boundaries in the narratives that take shape. An alter-ego figure functions as the narrator's representation of himself/herself, and in certain situations the supervisor may use an alter-ego figure in the supervision process. Wild and tame animal figures are used to express feelings and forces that find expression between those involved. For example, a bull can express powerfulness, while a little rabbit can be used to represent trepidation. A tortoise can be used to indicate how a person withdraws into his/her shell for protection, while a snake can be used to depict unreliability. The narrator chooses 
the symbols that express the emotions that need to be represented on the stage. The narrative receives support and emotional charge from tangible symbols. The actual image narrative presents a perception of a reality and the picture created remains clear in the memory.

*Externalization is a therapeutic technique developed by Michael White and David Epston; it belongs to the narrative school within systemic therapy. Externalization stems from the credo that "It isn't the person that's the problem - it's the problem that's the problem". Separating the problem from the person makes it possible to examine the interaction between the person and the problem. The problem thus becomes a separate entity outside the person.

\section{What IS PSYCHODRAMA?}

The other method is psychodrama. The word "psychodrama" comes from the Greek psyche (soul, life) and drama (action, theatre) and can be taken to mean "soul in action". The distinguishing features of psychodrama are that the person's internal, subjective images are displayed and given form, and are thus brought to life on the stage (Slettemark, 2004). Past, present and future can all be expressed in psychodrama. The internal images that are brought out into the open in the mini-theatre may have to do with incidents from the past, but they can also refer to circumstances in the here and now, and to the future. They may be unresolved situations, internal conflicts, fantasies and dreams. Everything is possible in psychodrama; numerous different perspectives can be represented on the stage at the same time in a single time dimension. Different realities can be merged, examined and brought to life on the stage. Psychodrama centers on bringing the action of the soul to life on stage.

Psychodrama is a theory and method that were originally developed by Jacob Levy Moreno as early as the beginning of the 1920s, and which have since been refined. Moreno has had a major influence in several areas, including group psychotherapy, personality psychology, sociology and social psychiatry. The method of psychodrama is an action method with numerous areas of application. It is a way of working that is used for therapeutic treatment, crisis processing, personal development, supervision of professional groups, leadership work and organization development. Moreno viewed psychodrama as a science through which the subjective truth can be explored using psychodramatic methods.

The work method in psychodrama comprises different "happenings" or phases, which are distinctive of the process. Psychodrama commences with a warmup phase. The purpose of the warm-up is to create a permissive and creative work climate. This phase often includes some elements of movement. It is during the warm-up that the group's shared topic appears; this topic is then carried forward by one of the participants, who is appointed to act it out on the stage. This participant becomes the key figure or protagonist for the group, which entails being the spokesperson for both the group and for himself/herself. The warm-up phase is followed by the action phase, which is the main part of the process. Following an initial interview, the role of auxiliary ego is allocated, the stage is set and the protagonist starts to act. The action phase is distinguished by role reversals with the assistance of the auxiliary egos, doubling, concretization and mirroring. The action phase often culminates in some form of catharsis, after which the drama begins to draw to a close. The psychodrama concludes with a dialogue or participation phase - often referred to as "sharing". During the sharing, the members of the group sit together and share their feelings and experiences from their role(s), or their own experience of relevant drama.

Psychodrama comprises a number of classic components. The first is the protagonist, the leading actor who carries the group's theme into a psychodrama. The second is the director, who works with the protagonist to create a sphere and an opportunity to bring the internal image to life. The third component part is the auxiliary egos, played by other participants in the group. These auxiliary egos (also called simply "auxiliaries") represent important characters in the psychodrama and help drive the process forward. The fourth is the audience, which comprises the other group members who are not up on the stage. The audience is often involved in the process and experiences benefit of its own, without playing an active role on the stage. The fifth component part is the stage, which is a part of the space in which the drama plays out. The stage may be equipped with props in the form of items of clothing, hats and figures that can be used as symbols during the psychodrama. A number of techniques are used in psychodrama, which are characteristic of the methodology. Role reversal involves the protagonist swapping roles with his/her auxiliaries on appropriate occasions in the drama. Role reversal entails swapping roles with another person and viewing the world and yourself through their eyes; this generates insight and empathy and can help reveal projections. Role reversal provides an opportunity to examine the situation and the interaction, and presents an opportunity to find new approaches in the circumstances depicted. Doubling is another psychodramatic technique that involves a member of the group being tasked with playing the protagonist's internal and non-expressed self - a "doppelgänger". Doubling entails an auxiliary taking on the persona of and identifying with - the protagonist and his/her thoughts and emotions, and then expressing them dramatically on the stage. The role of the Double is to 
represent the protagonist's psychological experiences in as much depth as possible. Another function is to provide the protagonist with support so that he/she dares to take more risks. Doubling can be used as support in a difficult scenario or, for example, to highlight conflicting emotions. The Double can also suggest to the protagonist a more appropriate way to behave in a given situation.

Mirroring is another technique that allows the protagonist to watch the unfolding scene while the auxiliary ego takes his/her place. The protagonist steps off the stage to obtain a better overview of the situation. On the basis of the new thoughts/insights the protagonist acquires through the mirroring, he or she can step back into the drama and try a new role.

Concretization is a technique that involves giving an inanimate object, a concept, a symptom or a thing a role on the stage as a dialogue partner - for example, a headache, stress, or a tree outside the window. Concretization provides a new opportunity for the protagonist to enter into dialogue with himself/herself.

These techniques are used to drive the psychodrama forwards. Emotions are liberated in action, but emotional representation and release only lead to change when supplemented by thought and knowledge-related insight. Psychodrama comprises both "head and heart" and its intention is to create "hands-on action insight" within the protagonist. The action insight is distinguished by three conditions. Firstly, it has to do with a personally perceived learning experience. Secondly, learning is achieved through doing.It is not sufficient to talk about what you need to do. Thirdly, learning is achieved at corporeal level. This action insight is achieved during the action phase. The subsequent phase - sharing - is the setting for an integration of emotion and cognition; feelings and understanding are linked together. This integration takes place within the protagonist, and often within the other group members as well.

\section{iV. "Frustration" - A Case Study}

This case study is drawn from a supervision process where both taping and psychodrama were used as complementary methods. The case study has been anonymized and no actual persons can be identified. The illustration depicts an emotional state expressed in the narrative.

The action takes place in a family center with a group of staff comprising school welfare officers and preschool teachers: Geraldine, Olivia, Caroline and Patricia. The family center is located in the suburbs of a large city. Facilities at the family center include an open preschool and facilities for providing counselling and support to individuals and couples.
In the supervision process, Geraldine - who is a school welfare officer - will be highlighting a problem issue under the header of "I'm so frustrated with a dad", based on a couples session she had with her colleague Olivia, who is also a school welfare officer.

The supervisor suggests that Geraldine use the taping material and set up the stage to illustrate the situation. Geraldine chooses alter-ego figures for herself and Olivia and places them on the stage. She then selects a figure for the mother - Lynne - and one for the father - Tom - and positions all the figures to represent where they were in the room during the session.

The participants are encouraged to choose symbols or animals to illustrate how they perceived the two parents. Geraldine chooses a large brown bull to represent obstinacy and places it behind the mother Lynne - and a sad, downhearted "Eeyore" to place behind the father - Tom.

Geraldine is then asked to choose a symbol for how she felt. She chooses a tiger, which she places behind her alter-ego figure.

"Well, that was what the emotional climate was like," says Geraldine.

Geraldine provides some background regarding the meeting. Lynne and Tom have two girls together, one aged four, the other 18 months. Tom also has a boy with ADHD from a previous relationship with Maria. Tom and Maria have shared custody of Daniel (aged 7), who lives alternately with each of his parents. While she is talking, Geraldine takes out figures for the two girls and places them close to their mother, Lynne. Daniel is positioned facing away from his father, Tom.

Geraldine relates that the parents, Lynne and Tom, sought external help when they discovered that Daniel has been playing sexual games with five-year-old Thea. The parents are now looking for help in how to find an appropriate way to confront Daniel with the situation and prevent any more incidents. By moving the figures farther away from each other, Geraldine demonstrates that Lynne and the children are distancing themselves from Daniel.

As the issue Geraldine is struggling with has to do with what happens within herself in relation to Tom, the focus is redirected towards Geraldine.

Geraldine is encouraged to show what is triggering her frustration. At this point, the representation moves from the figures on the table-top stage to a physical dramatization on the floor. A setting comprising four chairs is assembled on the floor. She then selects her colleague Caroline to play Tom and positions him on the chair in the center. No-one is chosen to play the roles of Lynne (the mother) and Olivia (Geraldine's colleague), but their chairs are positioned symbolically in the setting. Caroline takes on the role of Tom, sitting dejectedly in the chair with her head down.

The protagonist is asked to demonstrate what's happening. 
"How do you view your responsibility, Tom?" asks Geraldine.

The participants are encouraged to switch roles. Geraldine and Caroline swap chairs - and thus roles. Caroline takes on the role of Geraldine and repeats the line about how Tom views his responsibility.

Tom replies listlessly "I don't know ... I don't know ...". Tom speaks quietly with his upper body bent over.

The participants are asked to switch roles again. Geraldine and Caroline swap chairs once more and Tom repeats that he doesn't know how he sees his responsibility.

Geraldine now looks frustrated and is asked what she's feeling inside.

It is suggested that she stand behind her chair and verbalize her feelings, which she couldn't express in the real life situation. She is encouraged to let her thoughts and emotions find expression, to say what she's thinking and feeling. own chair:

Geraldine stands up and stands behind her

"Hey you! How about starting to take responsibility for your life! Grow up! You're a grown man. Start taking care of your kids instead of sitting there moping!"

Geraldine stops.

"Oh, goddammit! (silence) He reminds me of my brother. Luke!"

Geraldine is asked if she would like to bring her brother, Luke, onto the stage for a while.

She suggests that her colleague, Patricia, take on the role of her brother, Luke. Luke stands behind Tom to indicate that something in Tom reminds Geraldine of her brother, Luke.

Geraldine is asked what she feels she needs to say to her brother, Luke.

"Listen here, Luke, I'm so damned tired of having to take responsibility for you. It feels like I've been doing it all your life, as a kid and as an adult. But now it's time for you to start taking care of yourself! Take responsibility for your own life. Grow up!"

It is suggested that he has actually turned up at her workplace and that Geraldine physically has to take him away.

Geraldine stands up and escorts Lasse off the stage. "Now go home and stay there!"

Luke has now left the stage. Geraldine swaps roles with Tom again.

I ask the other two colleagues to go over and stand behind Geraldine's chair to reinforce the message of: take responsibility, grow up and take care of your children. I ask them to maximize the message to Tom.

After a while, I wonder what Tom is feeling and where his thoughts are going.
"I don't know what to do ... My ex is fighting me over custody - she wants sole custody of our son, Daniel. My current wife is micromanaging me; she plans everything from what we'll be doing on the weekend, to which clothes she thinks I should wear.

I just want to get away, to take my RV and drive as far away as I can. I just want to spend Saturday stretched out on the sofa, and not driving around on excursions all day. I don't want to answer the phone when it rings. I just want to be left alone!"

The participants are asked to switch roles.

Geraldine and Caroline swap chairs - and thus roles - once more. I ask the two Doubles to stand behind Tom to reinforce the message that he doesn't know how to act, and that he feels trapped.

Geraldine is replaced by a Mirror so she can look at the situation from a distance. Olivia becomes her auxiliary and takes on the role of Geraldine on the stage. The dialogue is repeated back so Geraldine can watch herself in the encounter with Tom.

"OK, I now understand how you feel, Tom." Geraldine moves back and sits in her chair, leaning in towards him. "I recall that you talked about a situation where you took the initiative and planned an activity together with your son. You said it felt good, and I saw your eyes come alive. You looked happy. I think I want to talk to you about when you take the initiative and suggest something you enjoy doing."

"Now that feels good! I don't feel the frustration that I was feeling to start with. I've developed some understanding for him and think I may have found ways to approach him in the conversation. We can wind this up here, it feels finished," explains Geraldine.

The psychodrama is concluded, the setting cleared away and everyone steps out of the roles they have been assigned. The group members then retake their places around the table with the stage and the figures, sharing the thoughts and feelings that arose during the action phase. There is now a period of mirroring on the basis of the taping image. The conversation concludes with recognizable trigger points that each and every member of the group can identify with - about which emotions are stimulated when others fail to take responsibility, are extremely passive or, in contrast, highly pushy and meddlesome. Geraldine's frustration becomes the entire group's concern, such that Geraldine's drama becomes everyone's drama.

V. Schema Theory and the Concept of MOdes

Schema theory is based on cognitive behavior theory (CBT), and is largely distinguished by emotions and underlying core cognitions. It is an integrative method developed during the second half of the 1980s by Jeffrey Young, DPhil, psychologist and psychotherapist, Columbia University. It is now an 
evidence-based psychotherapeutic model founded on CBT, attachment theory and gestalt therapy (Young, J., Klosko, J., Weishaar, M. 2003). We can apply parts of the theory in the taping methodology - primarily the part that has to do with modes. The following section presents a brief description of the theory behind schema therapy, coping styles and how the concept of modes can be applied in taping.

The systematic approach method used in schema therapy integrates techniques and strategies from different theories. Schema therapy shares similarities with cognitive behavior therapy in that both use cognitive and behavior interventions. One key concept of schema theory has to do with early dysfunctional schemas, which are the result of the individual's core needs not having been sufficiently accommodated during his/her life.

One of the fundamental concepts of schema theory is that we are all biological beings born with emotional needs - called "core needs" - consisting of security, autonomy, realistic demands and boundaries, as well as spontaneity and playfulness.

These core needs have to be covered in close relationships with others so as to allow the possibility of healthy development and maturity. When this happens, we develop healthy living patterns, known as "adaptive schemas". In situations where the fundamental patterns - our schemas - are frustrated, we develop early emotional wounds, "maladaptive schemas". The schemas that are developed here are defined by a combination of our temperament and experiences. These schemas are dysfunctional patterns and consist of thoughts, emotions, memories, cognitions and corporeal reactions. The following schemas can develop when needs are not met: abandonment, emotional neglect, distrust, shame, exclusion, under-developed self, failure, vulnerability to hurt, submission, confirmation-seeking, self-sacrificing, lack of selfdiscipline/self-control, emotional inhibition, punishing, overly strict demands and negativism/pessimism.

To avoid the risk of being drowned by the intensive, overwhelming emotions that our emotional wounds can cause us, we apply a variety of strategies to deal with them, known as "coping styles". These are the ways we react and express ourselves when our vulnerabilities are triggered. They are divided into the following categories: flight/avoidance, freeze/capitulation and fight/overcompensation. They help protect us against danger, discomfort and pain.

A coping style is thus a way to deal with vulnerabilities - a schema - for better or worse, but it does not heal the wound itself.

Jeffrey E. Young discovered that the original model of schema therapy was not sufficient. Focusing on dysfunctional schemas and coping styles was not enough to explain the phenomenon of changing behaviors, which is essential when the change process has to do with replacing dysfunctional patterns with more appropriate ones. It was on this basis that the concept of modes was developed.

A mode is the dominant, overarching state of mind in which a person finds himself/herself in a given moment. It encompasses the person's fundamental schema, vulnerability and associated coping style (avoidance, capitulation or overcompensation), and the coping response (the actual behavior) activated in the specific situation (a.a.).

Modes are divided into four categories: The first category centers on child-like modes; they are called the vulnerable child, the angry child, the impulsive child and the contended child. The second category refers to parent modes, i.e. internalized attitudes such as the punitive parent and the demanding parent. The third category consists of coping modes (derived from the coping styles), i.e. strategies for dealing with the situation; these are divided into the detached protector, the over compensator and the compliant surrenderer. The fourth and last category comprises healthy, welladjusted modes known as the healthy adult; it is also here that the contented child is to be found.

\section{Taping with Modes}

Taping can be used to help express a mode through the medium of symbols. When a mode is concretized with the assistance of a symbol, the act visualizes the dominant and overarching state or mind in which the narrator finds himself/herself at that moment in time. As the narrator is also asked to stage how the other person is perceived, the exercise also reveals the narrator's perception of the other person's mode. The table is thus the "stage" for the components that are perceived as strong influencers for the issue or the problem. The image presented now comprises information about the current status, which can then be examined and understood. The narrator is given the opportunity to express emotions and cognitions on the basis of his/her current mode/status, and, if appropriate, to use symbols to try other modes and see how that might change the issue/the problem.

The following section presents a case study drawn from a supervision process. The case study has been anonymized so that no actual persons can be identified. The illustrations depict the different emotional statuses that emerge during the narration.

In the supervision group, a counsellor brings up the need for help in "climbing out of a black hole". The counsellor, who we will call "Theresa", is currently feeling strong emotions of guilt and shame because her client has attempted to self-harm. Theresa starts the taping exercise by showing the situation using figures and symbols as occasioned by her current emotional state. The client, who is highly vulnerable on account of a problematic life situation and childhood, has taken an 
overdose and Theresa feels guilt and shame at having been unable to prevent this. Theresa chooses a figure for her client and lays it down. Next to it, she lays out figures representing her client' self-harming behavior.

Theresa continues to lay out the taping "stage" using figures and symbols to represent how this feels for her. She chooses a gun and points it towards her alterego figure. The supervisor indicates the gun and asks: "What does the gun mean to you?" Theresa answers: "You're a worthless therapist who couldn't see this coming and should've acted faster. It's your responsibility that this happened to your client." Her inner voice is punitive. On the basis of the concept of modes, the punitive and demanding parent mode is dominant in Theresa at the moment.

Theresa is asked if there is anything else she would like to show - anything else that affects the situation. Theresa continues her narration and shows the supervision group her current life situation, which is also having an influence on her. Theresa picks up figures that symbolize her family. She has attempted to be there for her young children, who have been ill, and for a seriously ill parent, about whom she is naturally concerned. Theresa places a heart on the stage as a symbol for the care she feels for them all. Theresa then chooses some figures to represent colleagues in her working group and shows how they have come and gone recently. Finally, Theresa sits her alter-ego figure down and says she feels utterly exhausted.

In the supervision group, taping is integrated with the reflecting team methodology, and at this stage the group members are asked to reflect on what they have seen and heard with one another, while Theresa has the chance to listen to what they are saying. The group members emphasize that they can clearly see and hear Theresa's warm empathy with other people, with her client, with her children and her parent. They have also noted her strong sense of responsibility and that she seems to lack others with whom to share this responsibility, both at work and at home. When the group members are asked whether they have picked up on any side of Theresa which has not found expression in the taping scene, one of them suggests a mother symbol. The participant places the symbol for "caring" next to Theresa's alter-ego figure. At the same time, she changes the position of the gun so that it is no longer pointing at Theresa's alter-ego. The gun is now on one side of her alter-ego figure, with the caring mother symbol on the other side.

Afterwards, it is Theresa's turn to reflect on the others' reflections, to accept whatever adds something to her and to discard whatever does not feel usable. Theresa nods and says that there is a caring side to her, but that it has always been directed towards people other than herself. The supervisor asks her to direct the symbol for the caring aspect ("healthy adult" mode) towards her alter-ego figure, to place her finger on the symbol and let it talk to her.

Theresa places her finger on the symbol and lets it talk to her alter-ego figure.

"It's an overwhelming situation for you. You've been far too alone in this demanding situation. So it's no surprise that you've felt unhappy. Now you understand why. You need to take care of yourself so you have the chance to recover. You need to share the responsibility with others."

In conclusion, the supervisor asks Theresa to look at the taping scene, to describe how it feels and what she has observed. To the question of how she feels now, Theresa replies that she feels better now, that she knows what she needs to do in future to take care of herself, and that it feels like she's no longer trapped in a black hole. She thinks that she's identified strategies both cognitive and behavioral strategies - for how she ought to think and act in future so that she will no longer feel powerless and dejected. She knows that she needs to share the responsibility with others around her.

Theresa states that she feels satisfied, and the supervision session is brought to a close.

The case study described above illustrates how the concept of modes can be used in taping. Concretizing dysfunctional modes - negative voices and discovering more positive modes - voices that can converse with the negative voice - can help change the internal emotions and the external dialogue.

Healing factors also encompass changes in behavior as the individual learns to replace dysfunctional coping styles with more functional ones.

Common mode constellations in taping are "the vulnerable child and the demanding parent", "the critical parent and the healthy adult" and "the vulnerable child and the detached protector". Taping allows an opportunity to externalize modes, and externalization, in turn, supports mentalization.

Having or developing a "healthy adult" mode entails being integrated in thought, emotion and action, as well as moving towards mutual satisfaction of needs in relationships.

\section{Vii. Concluding Reflections}

In the rebus "head, heart and hands-on", emphasis is placed on the specific and unique aspects of the methods "taping", "psychodrama" and "schema model", and on how the methods integrate the functions of cognitive analysis with the immediate emotional experience and active participation. Briefly put: head, heart and "hands-on" become one.

There are many similarities between taping and psychodrama, but there are several differences as well (Soltvedt, 2005 and Slettemark, 2004). The fact that both methods integrate head, heart and "hands-on", and that they are tangible, visual and creative methods, has 
made it possible to use the methods alternately in supervision sessions and to exploit their respective potentials. Both feature strong elements of non-verbal communication, which is an asset when the exploration of the problem is sensitive in nature, and when the exploration itself risks becoming over-intellectualizing. The mode concept from schema theory is a usable model in combination with taping and psychodrama, and which brings sharpness and distinction to the work method with its clean-cut forms of dominant states of mind in the moment (Young, J., Klosko, J., Weishaar, M. 2005).

In the methods of taping and psychodrama, the actors in the narrative act; they speak and express emotions. In taping, the drama takes place on a tabletop stage using acting figures, while in psychodrama, the narrator - the protagonist - physically acts together with his/her co-actors directly on the stage itself. In addition to the setting of a stage, taping and psychodrama share a number of significant component parts. Both have a leading figure - a protagonist - who tells a story, as well as an auxiliary ego on the stage, or other characters representing important people in the narrative. There is a conversation guide, or a "director", who helps drive the narrative forward. In both cases, the relationship between the narrator, the protagonist and the conversation guide (the director) becomes more cocreative, which allows the players to become more challenging and wondering, without becoming more directly inquisitive. Moreover, the other group members are present in both contexts, becoming involved in the process in different ways on the basis of the narrative as it unfolds.

The schema therapeutic perspective encompasses emotional, cognitive, behavioral and relation-related interventions, which makes the theory suitable for integration with taping and psychodrama. Schema healing factors include changes in behavior as the individual learns to replace dysfunctional coping styles with more functional ones. When a wound (a schema) heals, it is no longer triggered as readily as it was before. The concept of modes opens the door to internal dialogue between different sides of the person. Having or developing a "healthy adult" mode entails not only the integration of thoughts, emotions and actions, but also a mutual satisfaction of needs in relations with others.

There is much to be gained by combining the methods. Role reversal is to be found in both taping and psychodrama. Role reversal is the technique whereby the narrator/the protagonist swaps roles with another actor in the drama, and it is one of the principal techniques for reinforcing mentalization capacity. Role reversal makes it possible to view the world from the other person's perspective. Moreno expressed it as follows:
A meeting of two: Eye to eye, face to face. And when you are near I will tear your eyes out and place them instead of mine. And you will tear my eyes out and will place them instead of yours. Then I will look at you with your eyes and you will look at me with mine. Moreno

The same technique is to be found in taping, when the narrator places his/her finger on another person's figure and answers his/her alter-ego. Roll reversal, which boosts mentalization capacity, has to do with looking at oneself from the outside, and understanding the other person from the inside.

Mentalization capacity is supported in taping through the narrator "animating" his/her figures by moving them around the stage and speaking, thus taking on the perspectives, thoughts, emotions and needs of another person. Role reversal is also found in methodologies stemming from the schema model, with starting points drawn from gestalt therapy.

Switching from taping to psychodrama in role exchange reinforces the narrator's/protagonist's experiences and actions even further. In the first case study (about Geraldine), role reversal is used to amplify the emotional understanding of the client's perspective.

Concretization is to be found in both taping and psychodrama. Both methods can concretize the external as well as the internal representation within the narrator/protagonist, both separately and simultaneously. Taping allows inner images to be concretized - for example, the feeling that the person encompasses both a large, capable persona and a small, frightened one, which can be represented through the use of two different figures/animals/symbols. In the second case study (about Theresa), the punitive and demanding side of the figure are concretized in the form of a gun, while the caring side is represented by a mother figure. In psychodrama, an auxiliary ego can be cast as the large, capable persona, while another auxiliary takes on the role of the small, frightened one. In both cases, concretization allows the narrator/protagonist to engage in internal dialogue. The concept of modes, which covers a variety of states of mind in which the individual may find himself/herself, is one way to conceptualize and concretize the different sides the individual displays in a given situation.

In the first case study (about Geraldine), the narrator chooses symbols and animals to express how she perceives the states of mind of the other people involved - and her own.

Externalization is also to be found in both taping and psychodrama, and the concept of modes, in and of itself, is one way to externalize different sides of oneself and of others who are active in the situation. Externalization is a concept that is closely aligned with concretization. The technique is intended to separate the problem from the person so as to clarify that the person has a relationship to the problem-but is not the 
problem itself. Externalization of "partial selves" occurs when the narrator chooses different figures as representations of himself/herself, which clarifies how the narrator views his/her internal world, and those of others. When externalization takes place in psychodrama, the role of "partial self" is played by an auxiliary ego. The concept of modes in the schema model corresponds to the "partial selves" concept in psychodrama.

Doubling is a psychodramatic technique that it is beneficial to use in taping. In psychodrama, the group members have the opportunity to assist the protagonist in expressing messages and emotions that he/she finds difficult to bring out, by physically stepping onto the stage and expressing their emotions through the protagonist. In taping, I have developed a way for the group members to double the narrator during the reflection phase by placing their finger on the principal actor's alter-ego figure and suggesting messages. In the same way as in psychodrama, the narrator/protagonist always has the option of declining the suggestions put forward. Doubling can take place through the narrator's alter-ego figure, and through externalized modes.

In the first case study (about Geraldine), the doubles are used to reinforce the man's message that he feels trapped and that he doesn't know how to (re)act, so as to clarify his emotional state of mind.

Mirroring is a technique that appears in both psychodrama and taping but takes different forms in the two methods. In psychodrama, the protagonist steps off the stage while an auxiliary ego takes on the role of protagonist. The intention is for the protagonist to take advantage of the distance to gain a better overview of the happening and thus to come up with thoughts and ideas about what he/she should do in the situation. In taping, an overview is always available through the physical distance between the narrator and the figures on the stage. The conversation guide can switch between the narration playing out on the stage, and reflections derived from the overview that the scene provides.

In the first case study (about Geraldine), mirroring is used in the psychodrama section to allow the protagonist to gain distance from the situation, and to think about what needs to be done; in the taping section, it is used at the end to expand the narrator's topic to become the whole group's topic and thus to increase the recognition factor and the degree of urgency in the drama.

There are also similarities in how the process is concluded in taping and psychodrama. In taping, the activity is concluded by looking up from the scene playing out on the tabletop and reflecting on what has happened; how the narrative that has played out becomes useful to the narrator. It is in the conclusion phase that links are established between what happened on the stage and reality. What was created on the stage must, in one way or another, be applied in reality. The conversation is elevated to a cognitive level, concerns can be generalized and become issues for each and every member of the group. In the second case study (about Theresa), the session concludes with Theresa reflecting on the change that has taken place within her. She experiences having made a change, climbing out of her black hole and tapping into usable cognitive and behavioral strategies for how she should think and act in future.

In psychodrama, the session is concluded with a period of "sharing", where everyone present shares the emotions and perceptions they experienced over the course of the drama. During "sharing", an integration process takes place where emotions and understanding are merged. Both methods engender an experience of "I am not alone in my issue, my dilemma, my emotions ... they are something I share with others".

The miniature format of taping makes it possible to establish multiple stages at the same time; this creates structure and a broad overview of the happening. Presence in multiple settings can be built up simultaneously; different perspectives on one and the same issue can be illustrated in this smaller format, while the large format of psychodrama does not present the same opportunities. The taping stage can be used to visualize a helicopter perspective and keep the complexity alive. The different views of a mother and a father on a custody battle can be brought out at the same time.

Both methods are action methods and encourage people to express themselves in action. The actors - regardless of whether they are representative figures or actual people on a stage - can look at one another, look away, raise and lower their voices; the dialogue plays out in front of everyone's eyes. In the same way, different modes can enter into dialogue with each other.

The methods can move through different time perspectives: past, present and future. When characters address one another, they do so in the present tense; this augments both the sense of reality and the emotional temperature. In both methods, new dialogues can be tested between the characters. If the narrator/protagonist needs to find other ways to act, he/she can experiment with bringing new approaches to old situations. New dialogues can be trialed on the table-top stage or in the psychodrama before they are tested in reality.

In the first case study (about Geraldine), the process involves describing a situation that triggers frustration, followed by an emotional expression of feelings and then a thoughtful insight that leads to a change in and for the narrator. A similar scenario plays out in the second case study (about Theresa). In other 
words, head and heart working together with a view to creating insight into a hands-on action.

The originators of taping, psychodrama and schema therapy all emphasize the importance of play and creativity in the therapeutic work. Martin Soltvedt describes his desire to turn the conventional relationship between play and conversation upside down, with the purpose of tapping more strongly into the desire to play in the adult person in the change process.

For his part, Jacob Levy Moreno describes the psychodrama method as a method for allowing people to train their spontaneity. He believes that spontaneity is a precondition for allowing change. Creativity builds on spontaneity, and creativity is indispensable in the supervision process.

In his theory of schema therapy, Jeffrey Young $(2003,2010)$ describes spontaneity and playfulness having the opportunity to explore, to be curious and to tread new paths - as being one of our fundamental core needs. This core need has to be covered in relationships with others so as to allow healthy development and maturity to occur. The need to be spontaneous and playful, and to have the chance to explore, constitutes a key aspect in supervision. A survey of "active components" in supervision (Löwenborg, C. and Nilsson, L., 2002) highlights the importance of the supervisor creating a space for play, where the supervised person(s) can work with their material without fear or the need for justification. It seems that emotionally charged incidents are stored at a deeper level in our memory system and are processed more deeply in our brains, which makes it easier to associate with similar situations subsequently (Pakzad, F. from Psykoterapi, 2019).

\section{Vili. The Integration Process}

Supervision is a form of learning, and learning is an active process that benefits from involving different senses. The more senses that are activated, the more effective the learning usually becomes (a.a.).

Changing factors are the interaction between a cognitive processing, an emotional activation, and an adequate emotional encounter followed by a behavioral change.

An integration takes place between the different components. Head - Heart - Hands-on become One.

\section{References Références Referencias}

1. Berglind, Hans (1998) Skapande ögonblick. Falun. Cura.

2. Cullberg Weston, Marta (2010) En dörr till ditt inre. Visualisering i terapi. Ungern. Studentlitteratur.

3. Egelund, T. \& Kvilhaug, A. (2001) Supervisionens organisering. Socialvetenskaplig tidskrift nr 3.

4. Fox, Jonathan (1987) The Essential Moreno. Springler Publishing Company. New York.
5. Gyllenhammar, Carl \& Perris, Poul (2016) En klinikers handbok \& en terapiberättelse.

6. Höjer, S., Beijer, E. \& Wissö, T. (2007) Varför handledning? Handledning som professionellt projekt och organisatoriskt verktyg inom handikappomsorg och individ och familjeomsorg. FoU i Väst. PR-Offset, Mölndal

7. Josefsson, Dan \& Linge, Egil (2008) Hemligheten. Från ögonkast till varaktig relation. Finland. Natur \& Kultur.

8. Karp, Marcia, Holmes, Paul \& Bradshaw Tauvon, Kate (1998) The handbook of psychodrama. London and New York. Routledge.

9. Kellermann, Peter Felix (1992) Focus on Psychodrama. The Therapeutic Aspects of Psychodrama. London. Jessica Kingsley Publishers Ltd.

10. Lönn Hjertstedt, Harriet (2011) Tejpingens möjligheter. Gesällprov.

11. Löwenborg, C. \& Nilsson, L. Vad är verksamt $i$ handledning? Rapport 2002:2. Sollentuna. Bomanstryck.

12. Löwenborg, C. \& Nilsson, L. Vitryska utsiktsplatser (2005) Alfaprint, Sundbyberg.

13. Pakzad, Farzad (2019) Emotionell inlärning som en väg till ny kunskap i handledning.Psykoterapi 2019:1. Laholm. Trydells tryckeri AB.

14. Rydén, Göran \& Wallroth, Per (2008) Mentalisering. Att leka med verkligheten. Finland. Natur \& Kultur.

15. Slettemark, Gro (2004) Psykodrama ogsosiometri i praksis. Finland. WS Bookwell.

16. Soltvedt, Martin (2005) BOF - Barnorienterad familjeterapi. Falun. Mareld.

17. Van Wreeswijk, M., Broersen, J., Nadorf, M. (2012) Handbook of Schema Therapy Theory. Research and practice. Chicester. Wiley Blackwell.

18. Young, J., Klosko J., Weishaar, M. (2003) Schema Therapy. A practitioner's guide. New York. Guildford Publications.

19. Young, J., Klosko, J. (2010) Lev som du vill och inte som du lärt dig. Reinventing your life. Stockholm. NaturochKultur. 